\title{
União metodológica uma possibilidade de leitura e escrita filosófica
}

\author{
Róbson da Rosa Barcelos 29 \\ Vanderlei Vidal Zênero ${ }^{30}$
}

\begin{abstract}
Resumo: O presente panorama político-educacional sofreu mudanças com a obrigatoriedade do ensino de filosofia nas escolas de ensino médio do Brasil. Necessita-se pensar e re-pensar meios otimizadores do ensino de filosofia, onde leitura e escrita são os principais meios do pensamento filosófico na história. Destarte trabalhar com textos clássicos de filosofia, buscar novas metodologias eficientes ao ensino e aprendizagem filosóficos e promover a interdisciplinariedade tornam-se capitais. Assim unimos duas metodologias filosóficas para o ensino e aprendizagem de filosofia, a saber Porta (2002) e Gallo (2007). O segundo filósofo propõem quatro momentos para o filosofar: sensibilização, problematização, investigação e conceituação. Para Porta (2007) o leitor deve ser capaz traduzir e re-traduzir o texto filosófico, da seguinte forma: re-tradução semântico gramatical, re-tradução técnica, taxonomia semântica, re-tradução lógica e modalização veritativa. Durante o Programa Institucional de Bolsa de Iniciação à Docência nas produções textuais dos estudantes observa-se as posições perante os autores e o esforço em defender suas crenças contra as teses. Assim os discentes clarificam seu posicionamento, ou seja, sua "modalização veritativa". Portanto, mesmo existindo a distância temporal e linguística entre os alunos e os filósofos, isso não foi barreira para eles compreenderem o texto.
\end{abstract}

Palavras-chave: filosofia; ensino e aprendizagem; leitura e escrita; metodologia.

\section{Methodological union one possibility of reading and philosophical writing}

\begin{abstract}
This political-educational landscape has undergone changes with compulsory teaching philosophy in high schools in Brazil. Need to think and re-think optimizers means of teaching philosophy, where reading and writing are the main means of philosophical thought pervade the story. Thus work with classic philosophy texts; seek new efficient methodologies to philosophical teaching and learning; and promote interdisciplinarity become capital. So we join two philosophical methodologies for the teaching and learning of philosophy, namely Porta (2002) and Gallo (2007). The second proposes four stages to philosophize: awareness, questioning, research and conceptualization. For Porta (2007) the reader should be able to translate and retranslate the philosophical text, as follows: grammar semantic re-translation, technical re-translation, semantic taxonomy, re-translation logic and veritativa modalization. During the Institutional Program Initiation Grant to Teaching in the textual productions of the students observed the positions to the author and the effort to defend their beliefs
\end{abstract}

${ }_{29}^{29}$ Mestrando em Filosofia pela Universidade Federal de Santa Maria - UFSM robigolrobson@gmail.com

${ }^{30}$ Graduado pela Universidade Federal de Santa Maria - UFSM - acidnav@hotmail.com Revista Digital de Ensino de Filosofia - Santa Maria - vol.2., n.2 - jul./dez. 2016. 
against theses. So the students glorify their position, ie, its "veritativa modalization". Thus, there temporal distance and language among students and philosophers, was no barrier for them to understand the text.

Keywords: philosophy; teaching and learning; reading and writing; methodology

\section{Introdução}

Tendo como ponto de partida o retorno obrigatório da sociologia e filosofia enquanto disciplinas curriculares nas escolas de Ensino Médio do Brasil em 2008 (lei no 11.684) torna-se imprescindível pensar algumas questões específicas do ensino, da filosofia, suscitadas a partir desse contexto de inserção, e não tratá-lo como um mal menor ou simplesmente desprezá-lo31. A metodologia (procedimento) de Ensino e Aprendizagem da filosofia é obviamente exclusiva e, portanto, necessária de ser pensada, como é a preocupação de toda disciplina que compartilha este espaço.

Desde outrora a filosofia é produzida e transmitida através de três meios, o diálogo, a escrita e a leitura. Atualmente, entretanto, essas formas fundamentais sofrem uma relevante falta de incentivo que, por sua vez, culmina na dificuldade dos mesmos. O que, por sua vez, confirma-se na prática do ensino de filosofia na escola.

Se a filosofia é produzida e transmitida através destes três meios, não é prudente, portanto, ignorar suas dificuldades. Entretanto, seria absurdo deterse radicalmente a suprir tais dificuldades, não sendo atividade precípua da filosofia desenvolver especificamente a leitura e a escrita, embora desfrute destas. Esse problema se constitui o ponto nevrálgico deste projeto, a qual é dar atenção a tais meios e concomitantemente caracterizá-los com o pensamento filosófico a partir dos textos clássicos da filosofia, com uma metodologia peculiar que propicie essa atividade.

Assim, procurou-se desenvolver e testar uma metodologia que nos propicie a mediar o exercício filosófico do diálogo, da leitura dos textos clássicos e da escrita filosófica. Ademais, uma metodologia que possibilite trabalhar nesta via de mão dupla tanto o aspecto conteudista lou

${ }^{31}$ Como assim fizeram alguns filósofos, por exemplo, Abelardo, Schopenhaver e Etienne Gilson, tratavam o ensino de filosofia com uma ideia de "desprezo" ou "mal menor" para o filósofo. (OBIOLS 2002, p.89-94).

Revista Digital de Ensino de Filosofia - Santa Maria - vol.2., n.2 - jul./dez. 2016. 
enciclopédico) como de habilidades (competências) da filosofia sem, entretanto, colocá-los na contramão. Pois,

(...) precisamos fugir dos dois 'cantos da sereia' muito comuns nos processos educativos: 0 conteudismo (isto é, tomar o ensino como mera transmissão de conteúdos historicamente produzidos) e outro mais 'moderno', o discurso das competências e habilidades (isto é, tomar o ensino na contramão do conteudismo, como o desenvolvimento de determinadas habilidades e competências específicas). (GALLO, 2007, pg. 16).

Não se pode, por fim, esquecer o distanciamento existente entre estas duas instituições de ensino que produzem e transmitem nosso conhecimento, ou seja, universidade e escola. Este projeto de pesquisa e extensão, Projeto institucional de Incentivo à Docência (PIBID), em sua totalidade, procura estreitar os laços com estas duas instituições de ensino, proporcionando a formação prática e teórica aos acadêmicos do curso de filosofia da Universidade Federal de Santa Maria e formação continuada aos professores titulares das escolas onde o projeto está inserido.

\section{Objetivos}

Além de dar atenção às dificuldades, principalmente da leitura e escrita não filosóficas, esta pesquisa e extensão no âmbito da compreensão e produção textual, têm por fim também torná-las habilidades (competências) ${ }^{32}$ filosóficas, a partir do contato direto dos alunos com os textos clássicos de filosofia e consequentemente com o pensamento dos filósofos e não, indiretamente, por meio de manuais didáticos, pois:

Nos últimos anos, o debate relativo ao ensino de filosofia tem resultado em novas posturas, assim como no abandono de velhas concepções.

${ }^{32}$ Conforme explicita as Orientações Curriculares: Sob essa perspectiva formadora e de superação de um ensino meramente enciclopédico, desenvolveu-se a ideia de um ensino por competências (...), p.29. (...) Competências cognitivas, linguísticas e de ação, p.24.

Revista Digital de Ensino de Filosofia - Santa Maria - vol.2., n.2 - jul./dez. 2016. 
Pouco a pouco, vai sendo superada a ideia de restringir o ensino de filosofia no nível médio aos textos de manuais, ao mesmo tempo em que ganha força a proposta de promover um contato direto do aluno com o pensamento dos filósofos. (...) A leitura do texto filosófico, ou pelo menos de alguns trechos, deve ocupar um lugar importante no ensino de filosofia. (RODRIGO, 2007, p.48).

E promover também a interdisciplinaridade vista, nesse sentido, nas OCN's, como vocação da própria filosofia:

(...) a filosofia não se insere tão somente na área de ciências humanas. A compreensão da filosofia como disciplina reforça, sem paradoxo, sua vocação transdisciplinar, tendo contato natural com toda ciência que envolva descoberta ou exercite demonstrações, solicitando boa lógica e reflexão epistemológica. (OCN's, 2006, p.18)

Ademais, visa desenvolver e testar metodologias adequadas para se trabalhar com o texto (ou fragmento) em sala de aula e incentivar o hábito da leitura, escrita e do diálogo filosófico. Com isso também proporcionar formação continuada ao professor titular e aos acadêmicos do curso de Filosofia - Licenciatura culminando em uma maior aproximação entre universidade e escola.

\section{Método}

Tendo em vista a proposta de trabalho com a leitura e escrita filosófica, a partir dos textos clássicos da filosofia, busca-se uma metodologia adequada para tal trabalho. Adequada no sentido que permita um trabalho com a filosofia onde não se reduza ao seu aspecto conteudista (de mera transmissão de conteúdos) ou num ensino sem Conteúdo algum (comumente, "conversa oca").

Ademais, não se pretende com isso defender que a vivacidade da filosofia deve se enquadrar em um modelo de procedimento (método), nem este moldar a filosofia e o filosofar, conforme Aspis: 
(...) não acreditamos na possibilidade de um modelo para o ensino de filosofia. Não há como determinar um método para abarcar algo vivo, que está sempre sendo composto em um processo de constante devir como é a filosofia e como devia ser, aliás, toda educação. (ASPIS, 2009, p.81).

Portanto, com o devido cuidado, testou-se na prática o procedimento de ensino proposto por Gallo (2007) que consiste em quatro momentos, a saber, Sensibilização, Problematização, Investigação e Conceituação. Entretanto, o momento da problematização procede-se segundo a proposta de Porta (2002), dando assim um caráter peculiar a esse procedimento.

O momento da Sensibilização consiste em fazer o aluno se interessar pelo problema filosófico (ou temática) a ser trabalhado, ou ainda: "fazer com que os estudantes vivam, 'sintam na pele', um problema filosófico, a partir de um elemento não filosófico" (GALLO, 2007, p.28). É uma tentativa, portanto, de realizar uma aproximação, através de algo contido no cotidiano dos alunos, entre a vida destes e o que vai ser desenvolvido. A forma de trabalhar isso pode ser com:

(...) o uso de táticas mais descontraídas ou lqaté lúdicas que propiciassem que os alunos se sintam a vontade para expressarem livremente suas opiniões e sensações em relação ao material mostrado. Ainda não é momento de exigir quaver rigor, neste momento ainda não importa se tudo o que os alunos conseguirem seja mero senso comum ou até mesmo preconceitos, o objetivo é que se envolvam com a questão, que queiram investigá-la depois. (ASPIS, 2007, p.77).

Portanto, esse é um momento no qual o professor poderá (ou não) chamar os seus alunos para pensar acerca de um determinado problema ou tema que faça parte das suas vidas. Em outras palavras, o sucesso ou insucesso do docente depende muito desse momento.

O segundo momento do procedimento, o da problematização, desenvolve-se, então, a partir de Porta (2002), enfatizando-se nesta etapa a leitura filosófica do fragmento de um filósofo. Este entende a filosofia como 
uma atividade que procede basicamente por certos problemas. Portanto, o seu ensino e a leitura dos textos filosóficos devem ter como foco a problemática do filósofo, que muitas vezes não se apresenta de modo explícito no texto. Mas para chegarmos à compreensão de um texto filosófico é preciso a capacidade de fazer o que ao autor denomina tradução do texto, o qual é uma reconstrução do pensamento do autor de modo a nos possibilitar explicá-lo a outras pessoas. Dessa forma "Entender é 'traduzir'; ter entendido um texto é ser capaz de oferecer uma 'tradução' dele" (PORTA, 2002, p.55), ou seja, compreender o texto onde "Traduzir implica a possibilidade de retraduzir" (lbid, p.56). Essa tradução e re-tradução ocorrem, por sua vez, em quatro momentos: a re-tradução semântico gramatical, etapa na qual se procura explicitar o significado de termos que dificultam a compreensão e também transformar frases complexas em frases simples, eliminar conectivos; já a re-tradução técnica, é onde identifica-se os termos técnicos e suas definições, pois o filósofo pode usar termos do nosso vocabulário comum, mas com outro sentido; a taxonomia semântica traz os elementos propriamente filosóficos, como os argumentos, as definições, a tese, etc., mas todos esses aspectos tendo como centro o problema e a tese; e enfim a re-tradução lógica nessa fase final trata-se de ordenar logicamente o texto a partir do problema e da tese, obtendo uma versão mais reduzida, eliminando, desse modo, elementos secundários. É importante ressaltar outra questão importante para a compreensão do texto, o autor a chama de "modalização veritativa", isto é, o momento no qual o leitor passa a confrontar suas crenças com o pensamento do filósofo, assumindo uma posição:

Toda compreensão está ameaçada por uma certa 'esquizofrenia'. O leitor não vincula, mas mantém o que ele crê e o que o filósofo afirma em compartimentos estanques. Ele 'compreende' que, segundo Kant, a física supõe princípios a priori. Não obstante essa compreensão, ele não situa a tese crítica em relação à sua crença (que se mantém incólume) de que a física é uma ciência 'empírica' e que, como tal,se baseia unicamente na 'percepção'. Só quando deixamos por um instante Kant de lado e 'obrigamos' o nosso leitor a tomar consciência do que ele crê, é que ele percebe que propriamente não havia entendido o ponto 
de vista crítico sobre a questão. (lbid, p.72)

Portanto, a leitura filosófica de um texto, a partir de Porta (2002), depende desse trabalho de re-tradução e caracteriza-se pela identificação dos elementos centrais do texto: o problema, a tese e os argumentos.

No terceiro momento, de Investigação, continua-se com a leitura do fragmento, pois o objetivo é que os alunos, além de assumir uma posição a partir da identificação dos elementos centrais formadores do problema, extraiam elementos para a criação de seus próprios conceitos e referências para a solução dos seus problemas. Além do mais:

\begin{abstract}
Uma investigação filosófica busca os conceitos na história da filosofia que podem servir como ferramentas para pensar o problema em questão. Terá Platão deparado com esse problema? Em caso afirmativo, como ele pensou? Produziu algum conceito que tenha dado conta dele? $\mathrm{O}$ conceito platônico ainda é válido em nosso tempo? Ele dá conta do problema tal como o vivemos hoje? E na modernidade, Descartes e Spinoza lidaram com o mesmo problema? Criaram seus conceitos? (GALLO, 2007, p.29).
\end{abstract}

Percebe-se que neste momento é necessário visitar (ou revisitar) a história da filosofia. Essa visita a história da filosofia, a partir do foco do problema, resulta numa visão particular da mesma (Cf. Ibid). E pode-se fazer o mesmo a partir de outros problemas (ou temas) exercitando assim o pensar filosófico e ampliando cada vez mais a visão particular do aluno sobre a filosofia.

Por fim, o último momento do procedimento, a Conceituação. Esse é o momento no qual o aluno escreve sua própria posição filosófica perante o problema investigado a partir da leitura filosófica do(s) fragmento(s). Trata-se de uma recriação dos conceitos que formam e possivelmente solucionam o problema, pois:

Se na investigação pela história da filosofia encontramos conceitos significativos para nosso problema, trata-se então de deslocá-los para nosso contexto, recriando de forma que 
apresentem possíveis soluções; se, por outro lado, não encontramos conceitos que deem conta de nosso problema, certamente encontramos uma série de elementos que nos permite criar um conceito próprio. (Ibid, p.31).

Contudo, convém ressaltar que os momentos desse procedimento não estão desconexos. Além disso, podem ser adaptados de acordo com o contexto trabalhado pelo professor, de forma a melhor o auxiliar na sua prática pedagógica com a filosofia, seja em aulas ou oficinas.

\section{Revisão literária}

Todos os autores até aqui citados, Gallo (2007) e Porta (2002), por exemplo, não separam o procedimento de leitura dos textos filosóficos do próprio ato de pensar filosoficamente. Além daqueles, Folscheid \& Wunenburger (1997) e Cossutta (2011) também insistem que a preocupação com a metodologia da leitura filosófica não está desvinculada do ato de pensar filosoficamente.

Em Metodologia Filosófica a leitura e compreensão de textos filosóficos necessitam de um método filosófico, pois o modo de refletir sobre um texto filosófico já implica um ato de pensamento, o qual é filosófico. Destarte isso não é extrínseco ao filosofar, entretanto, percebe-se somente a repetição do pensamento filosófico. Assim, um método de leitura filosófica, não é algo exterior do pensamento filosófico:

(...) a preocupação metodológica ultrapassa, assim, largamente, a ambição utilitarista, uma vez que segue o movimento pelo qual a reflexão espontânea se transforma em pensamento filosófico. Ao praticar exercícios de filosofia, tratase de impregnar-se ainda mais de filosofia e, finalmente, de melhor filosofar. (FOLSCHEID \& WUNENBURGER, 1997, p.08).

O exercício ao qual Folscheid \& Wunenburger remetem-se é o da tensão existente entre o leitor e os pensamentos da tradição. Entretanto, o leitor guiase pela noção de explicação, para autores, que deve analisar e identificar o 
tema, a tese e os objetos de discussão (o assunto que está em voga, mesmo que de modo periférico, nas teses do autor), os movimentos do texto (sua estrutura) e as noções fundamentais. Portanto, a leitura e compreensão filosófica é demonstrada através da explicação, isto é, denotar o processo do pensamento do filósofo.

Também em Cossutta o acesso aos textos filosóficos depende do método, pois o texto filosófico contém partes reorganizáveis formadoras de uma unidade de sentido, porém essa só é atingível com sua reconstituição. Pois para Folcheid a filosofia contém certos traços:

\begin{abstract}
Isso nos encoraja a procurar os mecanismos gerais pelos quais a filosofia se produz como tal através dos textos: parece que, apesar da diversidade dos gêneros, das teses, dos modos de exposição, pode-se apreender funções bastante gerais que determinam aquilo que torna um texto propriamente filosófico. (COSSUTA, 2001, p.05)
\end{abstract}

Assim a leitura orienta-se por funções, a saber, "função sujeito" - que é a presença do autor no próprio texto, perceptível através de enunciados (dêiticos, pronome demonstrativo, etc.); função de endereçamento - isto é, onde o leitor se localiza, se encontra na maneira como o autor escreve; "função intertextual" - ou seja, a filosofia que é pretendida se apropriar, os saberes ou prática do momento que ele pretende questionar. A função sujeito exerce um papel central:

(...) mostraremos que, na verdade, os textos que colocam em cena o sujeito enunciador em primeira pessoa são bastante numerosos e que, se essa função parece frequentemente ausente, múltiplos rastros das operações enunciativas permanecem e desempenham um papel importante na estruturação das argumentações, análises conceituais e modos de exposição. (lbid., p.14).

Esta estrutura geral é um âmbito que deve ser ocupado por algumas funções textuais: conceitual, metafórico, dentre outros. Assim a cena filosófica, ou seja, a constituição do pensamento filosófico é o produto. Dessa forma Revista Digital de Ensino de Filosofia - Santa Maria - vol.2., n.2 - jul./dez. 2016. 
compreensão da relação entre as pessoas (autor-leitor-contexto) perpassa a leitura filosófica e a análise através do clarificar as operações que perfazem o sentido do texto (como as mencionadas: construção conceitual, etc.).

Nas OCN's o desenvolvimento de competências e habilidades também possui uma relação com a metodologia. Por exemplo, quando acontece "o exercício de busca e reconhecimento de problemas filosóficos em textos de outras naturezas, literários e jornalísticos..." (OCN's, 2006, p.37). Isso nos remete a proposta da "Sensibilização". Portanto, "a metodologia mais utilizada nas aulas de Filosofia é, de longe, a aula expositiva, muitas vezes com o apoio do debate ou de trabalhos em grupo." (Ibid, p.36), entretanto, esse "apoio" só será efetivo quando o aluno estiver "sensibilizado" para pensar filosoficamente sobre o problema, porém os textos não filosóficos muitas vezes impulsionam para uma aula não expositiva.

(...) com o cuidado de não substituir com tais recursos 'os textos específicos de Filosofia que abordem os temas estudados, incluindo-se aqui, sempre que possível, textos ou excertos dos próprios filósofos, pois é neles que os alunos encontrarão o suporte teóricos necessários para que sua reflexão seja, de fato, filosófica.' (lbid., p.38 apud Silveira, 2000, p.143).

Com isso se quer ressaltar a importância dos textos clássicos da filosofia que, de uma forma ou outra, todos os autores defenderam, e o procedimento e a leitura destes não são desconexos. É dessa maneira, portanto, que o filosofar a acontece, a partir do procedimento de leitura dos textos clássicos.

\section{Resultados e discussão}

Constata-se no fato, se tratando do aspecto não positivo, a dificuldade do aluno na hora da produção escrita, no que diz respeito ao português correto e na estruturação dos textos, e algumas vezes na própria leitura. Ou seja, as dificuldades são de leitura e escrita básica. Assim, percebe-se a importância e a necessidade de pensar procedimentos metodológicos do ensino de filosofia, a partir dos textos clássicos dos filósofos, os quais propiciem o desenvolvimento da leitura e escrita básica e, principalmente, filosófica. Revista Digital de Ensino de Filosofia - Santa Maria - vol.2., n.2 - jul./dez. 2016. 
Ademais, o ensino da filosofia também é afetado pelas turbulências inesperadas do cotidiano da escola (como greves, mudanças de horários e etc.) e com o pouco tempo disponibilizado para com os alunos. Portanto, muitas das influências que dificultam o ensino e aprendizagem da filosofia e do filosofar não dependem unicamente da filosofia para serem remediadas, se não solucionadas.

Entretanto, no aspecto positivo, constata-se a partir das produções textuais dos estudantes, apesar das dificuldades semântico-gramaticais, suas posições peculiares perante o autor. Nota-se o esforço em defender suas crenças contra as teses trazidas pelos filósofos. Nisso verifica-se um ponto positivo, pois há reflexão, dentro de suas condições, sobre o problema, ampliando seu conhecimento dentre os diversos lugares donde se olha uma questão filosófica. Igualmente sinaliza-se a tentativa do pensamento filosófico, onde se observa a utilização do cotidiano como recurso pedagógico para melhor explanação da compreensão do problema filosófico. Assim sendo os discentes clarificam seu posicionamento, ou seja, sua "modalização veritativa". Com isso, mesmo havendo a distância temporal e linguística entre os alunos e os filósofos, não foi barreira para eles compreenderem o texto.

\section{Conclusão}

Sendo assim, percebe-se a estreita relação existente entre esses elementos que constituem o ensino e aprendizagem da filosofia e do filosofar no contexto da escola atual, principalmente no que diz respeito à leitura e escrita a partir dos textos clássicos dos filósofos, através do procedimento aqui exposto, constituem "por si mesmo, não apenas um aprender a filosofar, senão um filosofar real, ainda que seja de forma embrionária" (OBIOLS, 2002, p.80). Portanto, se tal procedimento possibilita a aproximação dos alunos aos textos clássicos e a leitura destes resulta em uma escrita filosófica, embora embrionária, então, o procedimento (método) é válido.

\section{Referências}

ASPIS, Renata Lima. Ensinar filosofia: um livro para professores/Renata Lima Aspis, Sílvio Gallo. - São Paulo: Atta Mídia e Educação, 2009. 
COSSUTTA, Frédéric. Elementos para a leitura dos textos filosóficos. São Paulo: Martins Fontes, 2001.

FOLSCHEID, Dominique; WUNENBURGER, Jean-Jacques. Metodologia filosófica. São Paulo: Martins Fontes, 1997.

GALLO, Sílvio. A filosofia e seu ensino: conceito e transversalidade. In: SILVEIRA, René José Trentin; Goto, Roberto (Orgs.). Filosofia no Ensino Médio: temas, problemas e propostas. São Paulo: Loyola, 2007.

MINISTÉRIO DA EDUCAÇÃO. Orientações Curriculares para o Ensino Médio (OCEM), Volume 1: Linguagens, códigos e suas tecnologias. Brasília: Ministério da Educação Secretaria de Educação Básica, 2006. 2002.

OBIOLS, Guillermo A. Uma introdução ao ensino de filosofia. ljuí: UNIJUÍ,

PORTA, Mario. Filosofia a partir de problemas. São Paulo: Loyola, 2002.

RODRIGO, Lidia Maria. Uma alternativa para o ensino de filosofia no nível médio. In: SILVEIRA, René José Trentin; Goto, Roberto (Orgs.). Filosofia no Ensino Médio: temas, problemas e propostas. São Paulo: Loyola, 2007.

Um sentido para o ensino de Filosofia no ensino médio. In: GALLO, Sílvio \& KOHAN, Walter (orgs.). Filosofia no Ensino Médio. Petrópolis: Vozes, Vol. VI, 2000. 